\title{
Chemical Association
}

National Cancer Institute

\section{Source}

National Cancer Institute. Chemical Association. NCI Thesaurus. Code C73471.

Any process of combining chemical entities that is dependent upon chemical forces. 